\title{
Agnieszka Zduniak, Krzysztof Rubas, Uzależnienie młodzieży od internetu. Uwarunkowania społeczne i profilaktyka [Young Addicted to the Internet. Social Conditions and Prevention], Adam Marszałek Publishing House, Toruń 2021, pp. 217
}

\author{
Janusz Mariański \\ DOI: https://doi.org/10.15804/rop2021312
}

Contemporary media has a significant impact on improving our lives, especially the lives of young people. Media become an important element in shaping their personal and social identity, attitudes and everyday behaviors. They have enormous bonding power and great people connecting potential, regardless of one's geographical distance. Thanks to these means of social communication, it is possible to exchange information, ideals, values, norms and patterns of behavior. Science and technology have transformed our living environments and way of communicating, but also, in a sense, our way of thinking and acting. Under the influence of new digital technologies, basic models of social communication and interpersonal relationships are changing. The Internet is a widespread, complex and constantly evolving reality, especially for

${ }^{1}$ Higher School of Social Sciences in Lublin. ORCID ID: https://orcid.org/0000-00020620-8000. young people, for whom the web is now something very natural.

New technologies are really good for humanity. Yet, information in the network society, which is sometimes false, reaches all types of recipients, including children who use mobile devices that are constantly more efficient and handy. Access to the Internet is an elementary requirement for schoolchildren's function in today's world. Words and images can be sent to the most remote and secluded corners of the globe. The Internet enables unlimited expansion of the web and in many ways enriches one's social life. More and more Internet users find themselves in the virtual world of cyberspace, and some of them, overtaken with a virtual obsession, begin to isolate themselves and sever real social ties. The process seems difficult to stop and, to some extent, is even irreversible.

Sociologists emphasize that the online world creates great opportunities for establishing relationships that facilitate or complement direct relationships in the 
real world. Researchers are convinced of the positive influence of the Internet on interpersonal relations, claiming that it broadens and enriches social networks. Mass media multiply the possibilities of social communication, but at the same time limit interpersonal possibilities in the form of personal contacts, exchanging experiences and the direct transmission of values and norms. The Internet offers a new type of contact when anonymous web users meet on message forums to discuss issues and topics of interest. Those who are convinced about the Internet's positive influence on interpersonal relationships emphasize that it broadens and enriches social networks.

There is no shortage of critical opinions:

"It turns out that as people spend more and more time communicating online and organizing daily chores through the web, they spend less and less time nurturing face-to-face relationships. Some sociologists fear that the development of the Internet will deepen people's isolation and atomize society. They say that one of the effects of broad access to the Internet at home is that people spend less and less 'quality time' with their families and friends. The Internet has invaded the sphere of one's private life and blurred the line between work and home life: many people work overtime at home by checking e-mail or completing tasks that have been started and left unfinished. This leads to reduced contacts, neglect of relationships with others, the abandonment of traditional forms of entertainment such as theater or books, and a general weakening of social ties" (Anthony Giddens).

The Internet is associated with the danger and risk of becoming addicted, confusing the real world with the virtual one, replacing direct meetings and dialogue with people with contacts on the Internet.

Even if the Internet is a space where social contacts are condensed, it also isolates people from the problems of the real world. Many young people live in an imagined and created space. Contemporary youth, sometimes referred to as the digital generation, are aware of the enormous opportunities offered by new technologies in terms of links, communication and understanding between individuals and communities, making new friends, searching for information and news, sharing opinions and views, and creating new communities and networks. They allow us to meet and learn about the values and traditions of other people, nations and cultures. The variety of opinions expressed on the Internet can be perceived as valuable, but it is possible to limit oneself within the sphere of information that is in line with one's expectations and views, or with specific political and economic interests.

Social communication media play an increasing role in shaping consumer needs and desires, especially in societies that are moving from an economy of scarcity to an economy of abundance. Through com- 
mercials, films, series, game shows, etc., the media "tempt" us with an almost universal availability of consumer goods, promoting sumptuous and luxurious consumption by unifying the preferences of recipients. Even among those who struggle to meet basic material needs, "higher" consumer needs are awakened. Consumerism promoted from above by the media that develops from below in social life practice leads to the formation of a pragmatic consciousness, not always consistent with ethical consciousness, and sometimes this creates a specific "culture of emptiness." In a pragmatic consciousness, the freedom of the individual takes on the character of the freedom of the consumer (a culture of living the moment, promoting the cult of novelty and immediacy). The digital civilization intensifies the phenomenon of Internet addiction, which is worrying.

The phenomenon of Internet addiction is described and explained in various ways. The degree of this addiction can be measured in various ways, including: a) Internet preoccupation by constantly feeling the need to be in contact with others; b) Increasing one's time online; c) Repeated unsuccessful attempts to control, restrict or stop using the Internet; d) Spending more time on the Internet than planned; e) Feeling inner anxiety and even irritation when someone tries to limit or stop our use of the Internet; $\mathrm{f}$ ) Hiding one's excessive Internet fascination; g) When the Internet becomes a way of escaping from life problems or unpleasant situations; h) Using various internet technologies.

The authors of the study "Youth Addicted to the Internet. Social Conditions and Prevention" emphasize that the Internet is an integral part of one's social life, and the use of a computer and access to the Internet is a necessity in the modern world for everyone who wants to fully participate in the social, cultural, political and economic life. Yet, this virtual world that is expanding immeasurably also carries with it certain dangers. Both everyday observation and scientific research show that a person can lose control of the Internet and this leads to various types of addictions, including the limits of social pathology. Also, in Polish society, we are dealing with the inappropriate and compulsive use of the Internet, which has consequences in the sphere of a person's physical and mental health as well as in one's social functioning. The medium that is designed to serve people takes control of them and makes them addicted in various ways.

In the theoretical part of the study, the authors consider two basic issues in which they discuss: "Internet Addiction as a Behavioral Addiction" (chapter I) and "Addiction to the Internet" (chapter II). The reader learns about the controversy around the concept of netoholism, the essence of the phenomenon of behavioral addiction, the symptoms and diagnostic criteria of addiction, the causes of Internet 
addiction, and the physical, mental and social consequences of Internet addiction. Chapter II discusses in detail the problems of Internet addiction in the contemporary world: statistical data on risky Internet use, the social and health policy of European, Asian and North American countries towards the problem of netoholism, with particular emphasis on preventive measures and legal regulations, forms of psychological therapy and research on possible pharmacological treatment.

In the second rather practical part, the authors of the report indicate preventive measures aimed at making people aware of the risks and possible consequences of compulsive Internet use, but also at educating users of this medium to use it rationally and responsibly on a daily basis. They emphasize the role of social factors in the formation of addictions (social conditions) as well as preventive and therapeutic activities so that these new technologies are not a threat to humans, but become useful tools and man's effective ally.

The book provides reliable knowledge about the causes and effects of Internet addiction, providing important information on methods for preventing and treating Internet addiction. This issue is also shown in a specific, innovative universal prophylaxis program for students of lower secondary and upper secondary schools. The "Caught in the Net" program was implemented in 2013 by the Association for Supporting Activities for People Who
Need Help (DROGA) in Olsztynek and the Olsztynek community (301 people in total). The next stages of the project's implementation include: developing a universal prevention program, preparing and conducting training courses for implementers, a formative evaluation, an evaluation of the program's effectiveness, preparing an implementation and evaluation report, and preparing the final version of the program.

Using the Internet, a growing phenomenon in Polish society, brings with it profound changes in the way people communicate with each other. Yet, it can also cause unfavorable phenomena in the sphere of establishing and maintaining interpersonal relationships, as well as in the social awareness of Poles and their axiological sphere. Hence, the diagnosis of this phenomenon and taking preventive measures aimed at using new technologies is extremely important not only from the theoretical but, above all, from a practical point of view. The study should be an impulse for further empirical research, but also help in the development of new aid programs aimed at people showing symptoms of problematic Internet use, and - above all - people who are already addicted.

While research on the positive and negative consequences of the use of new technologies, especially the Internet, is quite advanced in the modern world, recognizing the negative consequences 
of using Internet resources in our coun- therapy are also important. This is what try is not yet sufficient. All activities the study entitled "Youth Addicted to the aimed at understanding the essence of Internet" addresses. The book will be of this phenomenon, disseminating social interest not only to representatives of the awareness of the risks associated with medical, social and educational sciences, the dysfunctional use of this medium as but also to those responsible for creating well as Internet addiction prevention and the social policy in our country. 